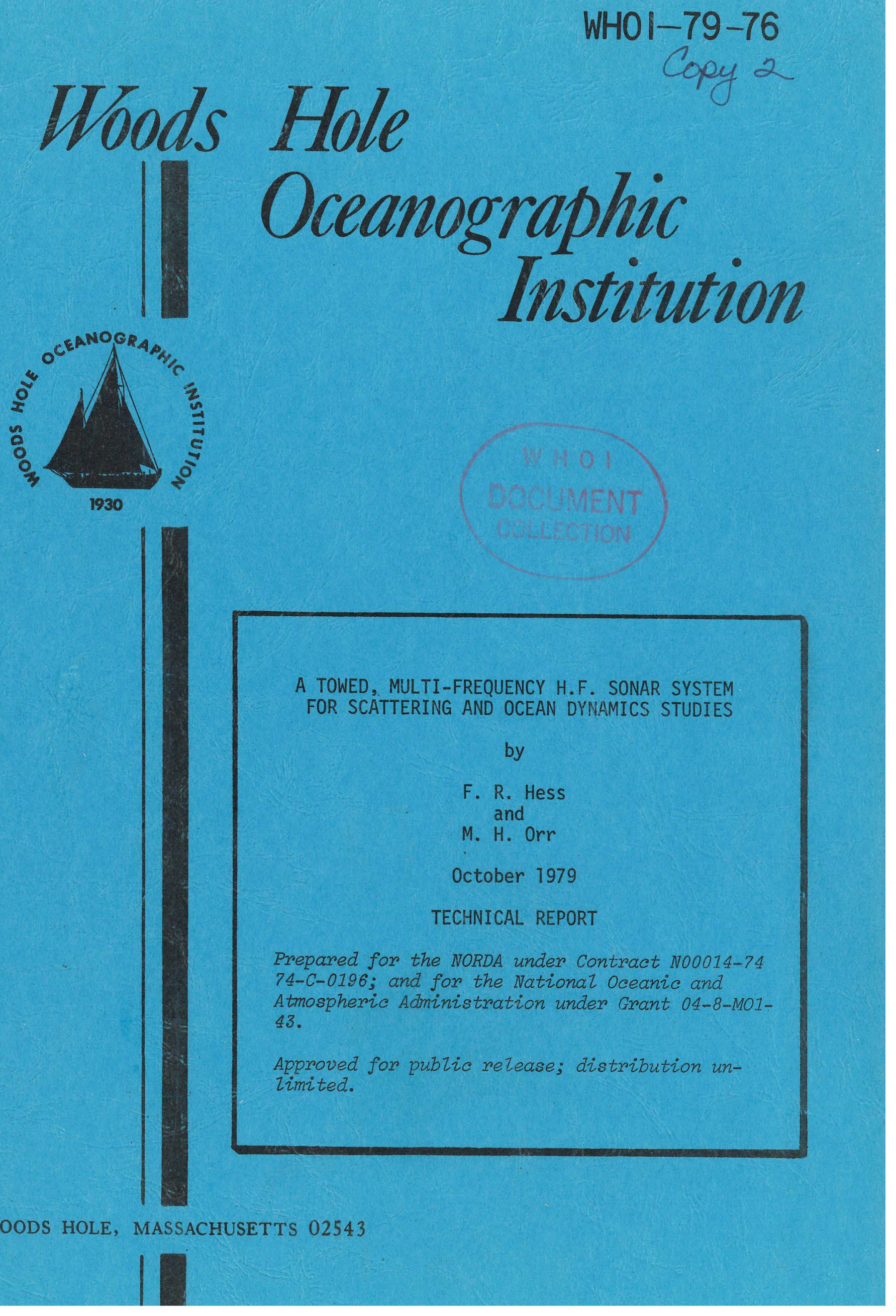


WHOI-79-76

\title{
A TOWED, MULTI-FREQUENCY H.F. SONAR SYSTEM FOR SCATTERING AND OCEAN DYNAMICS STUDIES
}

by

\author{
F. R. Hess \\ and \\ M. H. Orr \\ WOODS HOLE OCEANOGRAPHIC INSTITUTION \\ Woods Hole, Massachusetts 02543
}

October 1979

TECHNICAL REPORT

Prepared for the NORDA under Contract N00014-77-C-0196; and for the National Oceanic and Atmospheric Administration under Grant 04-8-M01-43.

Reproduction in whole or in part is permitted for any purpose of the United States Goverment. This report should be cited as Woods Hole Oceanographic Institution Technical Report WHOI-79-76.

Approved for public release; distribution unlimited.

Approved for Distribution Earl \& ldeay?

Earl E. Hass, Chairman

Department of Ocean Engineering 
TABLE OF CONTENTS

$\begin{array}{lc}\text { Abstract } & \frac{\text { Page }}{i} \\ \text { Background } & 1 \\ \text { System Philosophy } & 3 \\ \text { Receiver } & 3 \\ \text { Transmitter } & 3 \\ \text { Recorder and Control } & 3 \\ \text { Transducers } & 4 \\ \text { System Operation } & 4 \\ \text { Results } & 8 \\ \text { Conclusion } & 8 \\ \text { Acknowledgements } & 9 \\ \text { References } & 10 \\ \text { Figures } & 11\end{array}$




\begin{abstract}
The system described provides wide operational flexibility at any operating frequency from $5 \mathrm{kHz}$ to over $800 \mathrm{kHz}$ (except for a smal1 band around $455 \mathrm{kHz}$ ) limited mainly by the availability of transducers. Variable pulse width, variable receiver bandwidth, low receiver noise, various time variable gain functions and wide system dynamic range characterized the system. Built-in timesharing controls maximize flexibility of graphics display on either dry-paper or fibre-optic CRT recorders.
\end{abstract}




\section{A TOWED, MULTI-FREQUENCY H.F. SONAR SYSTEM FOR SCATTERING} AND OCEAN DYNAMICS STUDIES

\section{BACKGROUND}

Developing interest, based on the work of $\mathrm{Munk}^{1}$, Proni ${ }^{2}$, and Fisher ${ }^{3}$ and others, in the investigation of a variety of sha1low ( $<200 \mathrm{~m}$ depth) phenomena at the Woods Hole Oceanographic Institution led in the mid-70's to a requirement for a high resolution sonar system. Early tests, to determine feasibility, utilized several types of commercially available echo sounders which had been modified to increase the available gain and to improve frontend noise performance. These tests, in which a variety of frequencies, recording schemes and towing configurations were tried, aimed at determining not only the feasibility of acoustically studying the various particulate regimes and the hydrodynamic phenomena outlined by them, but provided sufficient data to establish design parameters for an optimum system.

1. The most important requirements were determined to be: Wide operating frequency range. Since the acoustic "targets", either individual or diffuse, vary in size from submillimeter range to a few centimeters, frequencies from a few $\mathrm{kHz}$ up to several hundreds of $\mathrm{kHz}$ are required in order to optimize both resolution, target detection, and the ability of the system to determine the dominant scattering mechanism being observed at a particular location.

2. Low system noise 1eve1. In order to obtain a11 possible information from the target echoes and to increase system detection ranges, system noise (i.e. receiver front end noise) must be lower than the received ambient noise from the sea in the bands of interest. Sea state zero noise (Knudsen ${ }^{4}$ ) varies from about $-50 \mathrm{db}$ re $1 / \mathrm{dyne} / \mathrm{cm}^{2}$ spectrum level at one $\mathrm{kHz}$ to a low (theoretical) on the order of -80 to $-90 \mathrm{db}$ in the $90-100 \mathrm{kHz}$ range, rising again with frequency as a result of increasing molecular motion as this minimum is passed. 
Practical limits on transducer sensitivity, typically -75 to $-95 \mathrm{db}$ $\mathrm{re} /{ }^{1} \mathrm{vol} / \mathrm{t} / \mathrm{dyne} / \mathrm{cm}^{2}$ frequent1y require receiver "front ends" with equivalent input noise -20 to $-30 \mathrm{db}$ below one microvolt $(-140$ to $-150 \mathrm{db} \mathrm{V})$. Such low noise performance requires careful design and component selection.

While such low noise figures are not always useful, especially at frequencies below $50-60 \mathrm{kHz}$ due to the combined effects of ship generated noise and flow noise around the tow body, occasionally the ship is stopped and allowed to drift. In this mode all available useful sensitivity is put to work.

3. Wide system dynamic range. In order to be able to detect the low signal levels resulting from the anticipated scattering mechanisms as well as to be able to measure reflectivity (target strength) of large discrete targets, the system must be able to pass and display signals ranging in amplitude over three or four decades (60-80 db). Since no existing display medium can approach this dynamic range, two techniques are commonly employed; "tapped" gain stages and some form of time-variable-gain (TVG).

4. Flexibility. In order to make the system as adaptable as possible to various research/survey vessels, it must be configured for towing of the transducers in a simple "fish". A suite of transducers must be provided for operation at a variety of frequencies such as: $20 \mathrm{kHz}, 100 \mathrm{kHz}, 200 \mathrm{kHz}, 300 \mathrm{kHz}$, and $500 \mathrm{kHz}$. Other transducers may, on occasion, be used with the system and, in fact, virtually any transducer should be usable. A set constructed especially for this system however would provide certain features such as commonality of mounting and connectors and would be physically interchangeable in the tow-bodies. 


\section{SYSTEM PHILOSOPHY}

$\underline{\text { Receiver }}$

It was decided, based on the earlier work, that the mix of analog and digital circuit systems would emphasize digital control and frequency generation, but be completely analog in the signal processing (Figure 1). The receiver is required to tune the $5 \mathrm{kHz}$ to $800 \mathrm{kHz}$ frequency range, be easily tuned to various frequencies in this range, and all channels must be interchangeable. Digital control is felt to be desirable if for no other reason than repeatability. Receiver bandwidths must be constant and repeatable from one operating frequency to another. Receiver blanking and signal gating must be provided. Two forms of repeatable time-variable-gain (TVG) are required.

The use of a superheterodyne receiver allows for tuning by digital control of the synthesizer used for the local oscillator. Uniformity of response at different frequencies is readily accomplished with the use of Intermediate Frequency (IF) filters. System overall gain is readily adjusted and gain stability is good. Any frequency within the design range, except the sma11 band of frequencies around $455 \mathrm{kHz}$ can be received with equal facility. Transmitter

The transmitter requirements are straight forward. The wide frequency range and repeatability requirements again press for synthesizer control. Variable pulse width, in number of cycles transmitted also dictates the use of digital control. The low duty cycle of a sonar system, typically less than one or two percent, allows for the generation of high pulse power in a sma11 physical package.

Recorder and Contro1

The system must be capable of full control of the recorder used (EPC 4600). Al1 necessary timing, gating and drive signals are to be provided. 
Transducers

A set of transducers and associated tow bodies are provided. At $200 \mathrm{kHz}$ a beamwidth on the order of one degree is required while at the lower frequencies (20 and $37 \mathrm{kHz}$ ) beamwidth of 15 and 6 degrees respectively are dictated by the space available.

\section{SYSTEM OPERATION}

The system block diagram (Figure 2) shows the major functions provided which are necessary for the acoustic mission. Not shown are the various clock, control and time sharing functions as they would clutter up the diagram and are conventional.

In order to maintain optimum noise performance, the preamplifier is in the tow body. It utilizes a low noise $(<6 \mathrm{nv} / \sqrt{\mathrm{Hz}}) \mathrm{FET}$ front end followed by a remotely programmable gain amplifier/1ine driver. Gain is controllable in four steps: $25,35,45,55 \mathrm{db}$, by front panel switch.

Transmit-receiver $(T / R)$ switching and preamplifier protection is by means of Shottky diodes. This method costs some power in transmit but results in minimum switching time for examination of very close returns and little degradation of noise performance. Back-to-back Shottky diodes effectively disconnect the transmitter during receiver time minimizing noise from the power amplifier or pickup on the transmit line.

Provision is made for insertion of "calibration" signals into the preamplifier. The "cals" are rather for establishing that there has been no degradation of system performance during an operation than for determining absolute gains. These are established in the laboratory.

A11 of these functions and controls mandate the use of a multi-conductor towing cable. The system uses TTRSA-8 (8 twisted/shielded pairs) cable for the electrical function. The preamplifiers are packaged two per pressure housing giving two frequencies (channels) fed from a single cable. 
On deck a $25 \mathrm{db}$ line amplifier is available for raising signal level if necessary. The first functional stage of the receiver is a four quadrant multiplier which provides both manual gain and time-variable-gain (TVG) action. TVG ramp generation is by means of two multiplying digital-to-analog (D/A) converters and counters which count up from zero to full scale (10 V) in whatever graphic recorder display scale is selected. That is, irrespective of the sweep speed or display split (detailed later) selected, system gain is minimum immediately after the transmit pulse and rises to maximum at the right hand edge of the display at whichever rate is selected. Linear ramps $(1 / t)$ are available from a single $\mathrm{D} / \mathrm{A}$ while $1 / \mathrm{t}^{2}$ ramps result when the output of the first D/A is used as the reference for the second while both are seeing the same digita1 inputs.

Manual gain is accomplished with a potentiometer and a fixed DC voltage. Typically, system electronic noise is printing full black at the right margin and all echoes are below detection threshold.

After spreading correction, the signal is heterodyned with digitally generated local oscillator (LO) in a balanced mixer. The difference between the signal and local oscillator is the intermediate frequency (IF). Keeping the local oscillator on the high side of signal results in the image frequency being separated widely from the desired input. This is necessary as the only tuning at the signal frequency is that accomplished by the transducer and its tuning inductor. Low side (SUM) operation would make the system vulnerable to low frequency noise which is generally strong at sea.

The local oscillator is a single card, commercially available, digitally programmable synthesizer. Front panel thumbwheels set the operating frequency to which 455.0 is added to program the LO synthesizer to provide the proper heterodyne frequency. 
Following the mixer, a CMOS dual one-of-eight analog multiplexer selects the desired ceramic IF filter. Filter bandwidths (6 db) of 35, 30, 26, 20, 16, 12, 8, and $6 \mathrm{kHz}$ are available. The filters have 1ess than 2:1 shape factors (ratio of $6 \mathrm{db}$ BW to $60 \mathrm{db}$ BW). The dual multiplexer selects both filter input and output minimizing feed-through of extraneous signals.

Following the filter is an integrated IF amplifier (Motorola MC 1350P) set for $20 \mathrm{db}$ gain. This in turn feeds another multiplexed filter set selected along with the first set. Finally, a second MC1350P completes the IF strip with a conventional IF output transformer.

At the input to the first and second IF stages and at the output of the second, a simple half-wave detector using a germanium diode and a short time constant ( $\sim 50 \mu \mathrm{S}) \mathrm{RC}$ network is connected. These detectors each feed a simple DC amplifier. This amplifier has selectable voltage gains of 0,6 , 12, 18, 24, and $30 \mathrm{db})$. The DC amplifier output is fed to the output terminals through mercury-wetted relay contacts which are keyed to perform the timesharing function by simply connecting the outputs of two receivers in parallel. A $10 \mathrm{~K}$ resistor in series with each front panel output prevents inadvertent overloading of the signal by outside measurement systems. The rear apron outputs do not have series resistors and are designed for all quantitative measurements.

A scan split control is provided which consists of a one-digit thumbwhee1 switch. This circuit breaks the sweep (of an EPC recorder) into 10 segments. The sweep may then be split (time-shared) between two frequencies with the thumbwheel selecting the number of tenths (of the sweep) displaying the first frequency. While the sweep is generally split in the middle, it is often useful to use more than half of the display for the lower frequency as its range may be greater than a higher one.

Transmitting is controlled by two means: A front pane1, 2-digit thumbwheel switch selects the number of cycles in the transmitted burst and the voltage 
control on the power amplifier sets the output stage collector voltage and thereby, output power. Frequency setting of the transmit synthesizer is done by the receiver frequency thumbwheels.

A set of transducers and at least three types of tow body have been constructed for use with the system. The transducers, three single-frequency units housings and mounting dimensions. Connectors are not identical to prevent improper transducer-to-amplifier connection. The transducers are close packed arrays of thickness mode discs for all frequencies above $200 \mathrm{kHz}$. At $20 \mathrm{kHz}$, bimorphs are used to form the array and at $70 \mathrm{kHz}$ Langevin stacks are used.

One lightweight tow body carries two transducers and is generally used from small craft with one two-frequency system. The second "1ightweight" towbody (Figure 3) carries three transducers which, if the dual-frequency transducer is used, allows four-frequency operation.

A MK-43 torpedo has also been modified as a tow body with the capability of mounting three transducers as well. It is capable of higher towing speeds and is used where adequate handling and towing gear is available.

System display is by means of EPC 4600 dry paper graphics recorders. A11 drive timing for the recorder is provided by the system. Sharing provisions are made such that two systems (dual frequency) and their associated recorders can be synchronized, thereby providing four-frequency operation.

The system clock provides IRIG "B" time code for magnetic tape logging as well as keying, scan splitting and time sharing controls. All operation is from an internal crystal oscillator with no reference to the power line. Figure 4 shows two dual-frequency systems (or a single four-frequency system and all ancillary components. Tape recorders for each pair of frequencies are provided as is a fibre-optic CRT recorder with variable delay trigger for fine seal recording of any of the four acoustic channels. 


\section{RESULTS}

In mid-1977 two systems were completed and sent to sea simultaneous $1 \mathrm{y}$ on the NOAA ships MT. MITCHELL and ALBATROSS to study the dispersion of chemical wastes released from a barge at Deep Water Dumpsite 106 (DWD 106).

During transit to the site aboard ALBATROSS, a layer of heavy scattering, presumed to be biological, was observed over long lines of track at a depth of 30-40 meters. This 1ayer undulated gently with peak-to-peak amplitudes of 2-3 meters over distances on the order of a kilometer for the most part. Occasionally however, cuspoid wave packets, consisting of 4-6 cycles with amplitudes of 15 meters or more ( $\mathrm{p}-\mathrm{P})$ appeared. The packets were intriguing and their origins can only be hypothesized.

Observation of the plume from the dump oricess, consisting, we were informed, of flocculates of insoluble iron compounds recipitated from the waste by reaction with sea-water, was carried out and the dispersion rates determined. Rates of lateral dispersion as well as sink rates of the flocs were determined. The tendency of the waste to spread out on a density/ temperature surface was observed. The system was working better than hoped.

During the return trip to Woods Hole a series of zig-zag traverses across Hudson Canyon provided startling graphics of the various water masses at work in that area including a lenticular, low-scattering intrusion running down the axis of the canyon (Figure 5). XBT data taken at the time, as well as a rosette sampler lowering (which shows on the recording), verified that the reflecting horizons correspond to temperature gradients. The samples analyzed showed particulate concentrations on the order of 60 micrograms/1iter total particulates at 90 meters.

\section{CONCLUSION}

The system provides the necessary acoustic flexibility and performance to 
observe the phenomena to be studied. Current flows delineated by particulate suspension have been mapped at depths in excess of 100 meters. The scattering mechanism which provides the return is not unequivocally known in all cases, but there is strong indication that temperature and/or turbulence provide sufficient backscattering for mapping.

The system provides the desired tool and has been in operation for over two years with continuous upgrading of performance.

\section{ACKNOWLEDGEMENTS}

Funding for construction of the "ideal" system was provided by both NOAA (04-8-MO1-43) and NORDA (N00014-77-C-0196). 


\section{References}

1. Munk, W. H. and Garrett, C. J. R., Internal wave breaking and microstructure, Boundary Layer Meteoro1., 4, 45-47, 1973.

2. Proni, J. R. and Ape1, J. R., On the use of high-frequency acoustics for the study of internal waves and microstructure, J. Geophys. Res., 80, 1147-1151, 1975.

3. Fisher, F. H. and Squier, E. D., Observation of acoustic layering and internal waves with a narrow-beam $87.5 \mathrm{kHz}$ echo sounder, J. Acoust. Soc. Am., 58, 1315-1317, 1975.

4. Urick, R. J., Principles of Underwater Sound for Engineers, McGraw-Hi11, New York, 1967, pg. 167. 


\section{Figures}

Figure 1 Front pane1 of the high frequency sonar system showing all major controls and connections. Two transmitters (outer modules) and two receivers (inner) and a common timing/control module are shown. Not shown is another smaller panel containing the 1200 watt power amplifiers which could not be sufficiently isolated from the digital electronics when installed in the main frame.

Figure 2 System Block Diagram

Figure 3 Fibreglass towbody which contains three transducers for use during four frequency operations. Separate transducers for $20 \mathrm{kHz}$ and $200 \mathrm{kHz}$ are mounted as well as a dual, $357 \mathrm{kHz} / 520 \mathrm{kHz}$ unit. Preamplifiers, $T / R$ networks and transducer matching networks are carried in two small lexan cylinders inside the towbody.

Figure 4 Two dual frequency H.F. sonar systems comprising a single four-frequency system. The rack at right contains a fibre-optic CRT recorder for high resolution work as well and a variable persistence oscilloscope and camera used for dynamic studies. Lower units are for temperature and depth recording.

Figure 5 Section of $200 \mathrm{kHz}$ recording on flanks of Hudson Canyon showing up to nine identifiable reflecting.scattering surfaces. The staircase in the center was made by the lowering of a CTD/rosette sampler. A temperature plot shows good correlation with acoustica11y mapped layers. 


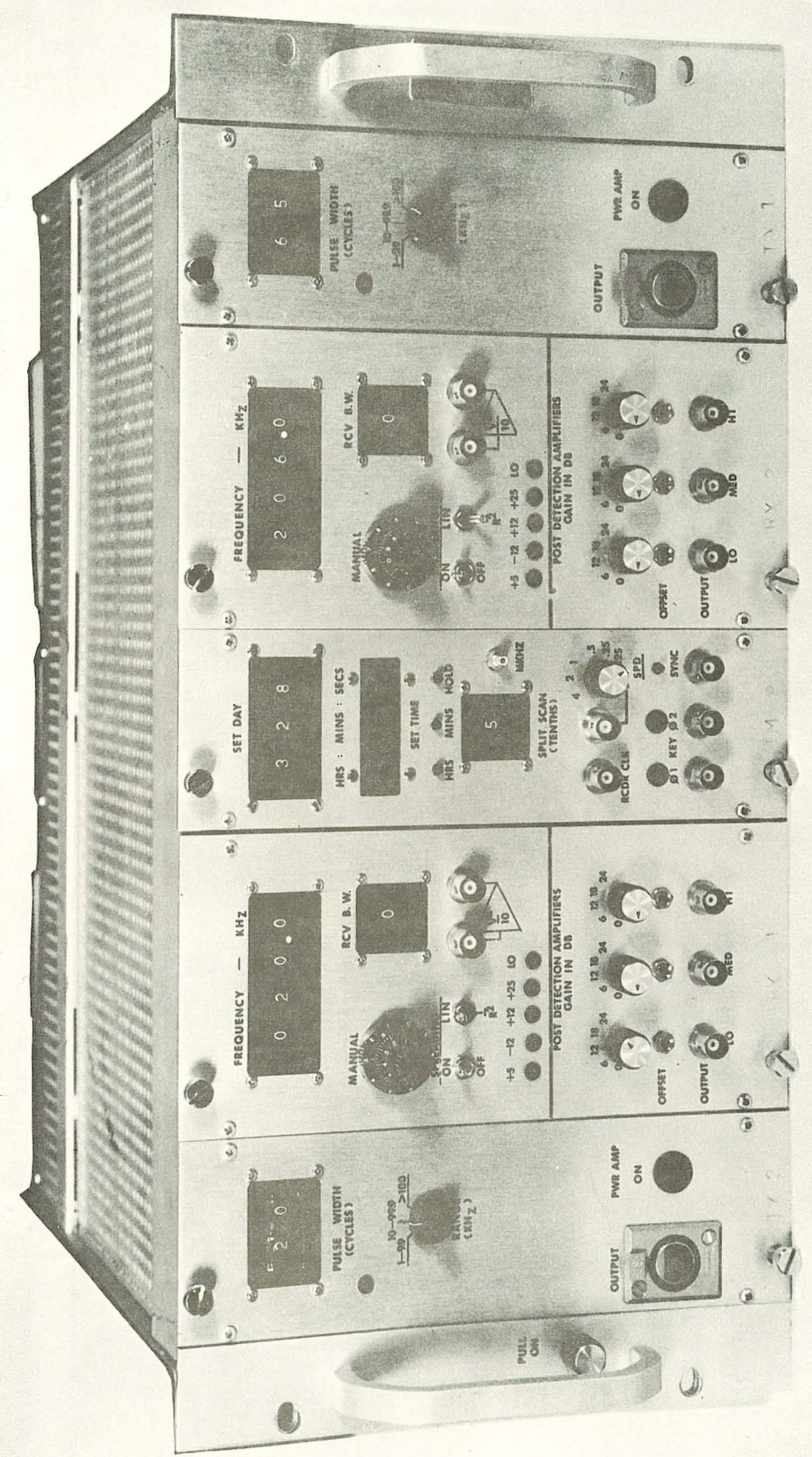




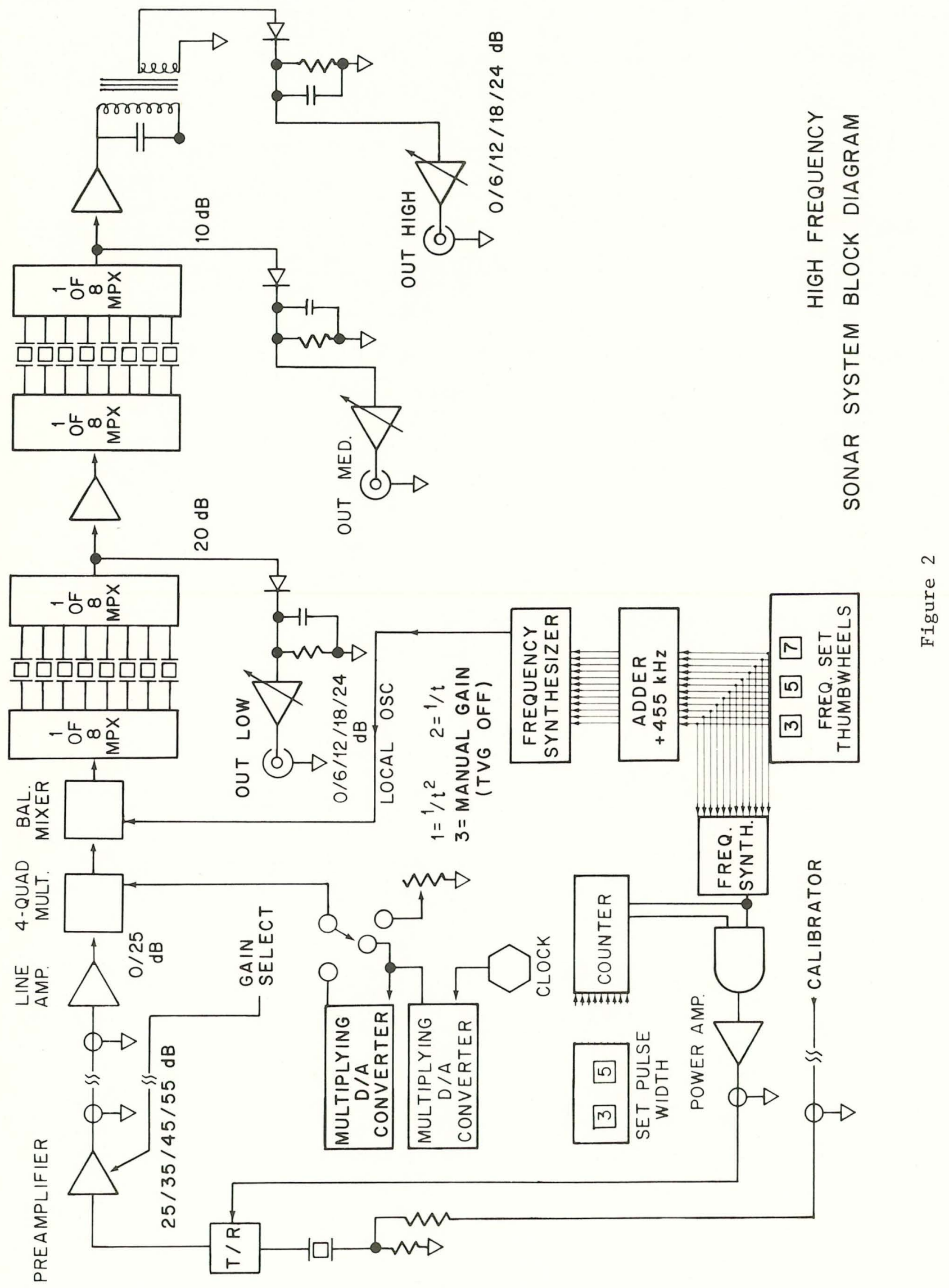




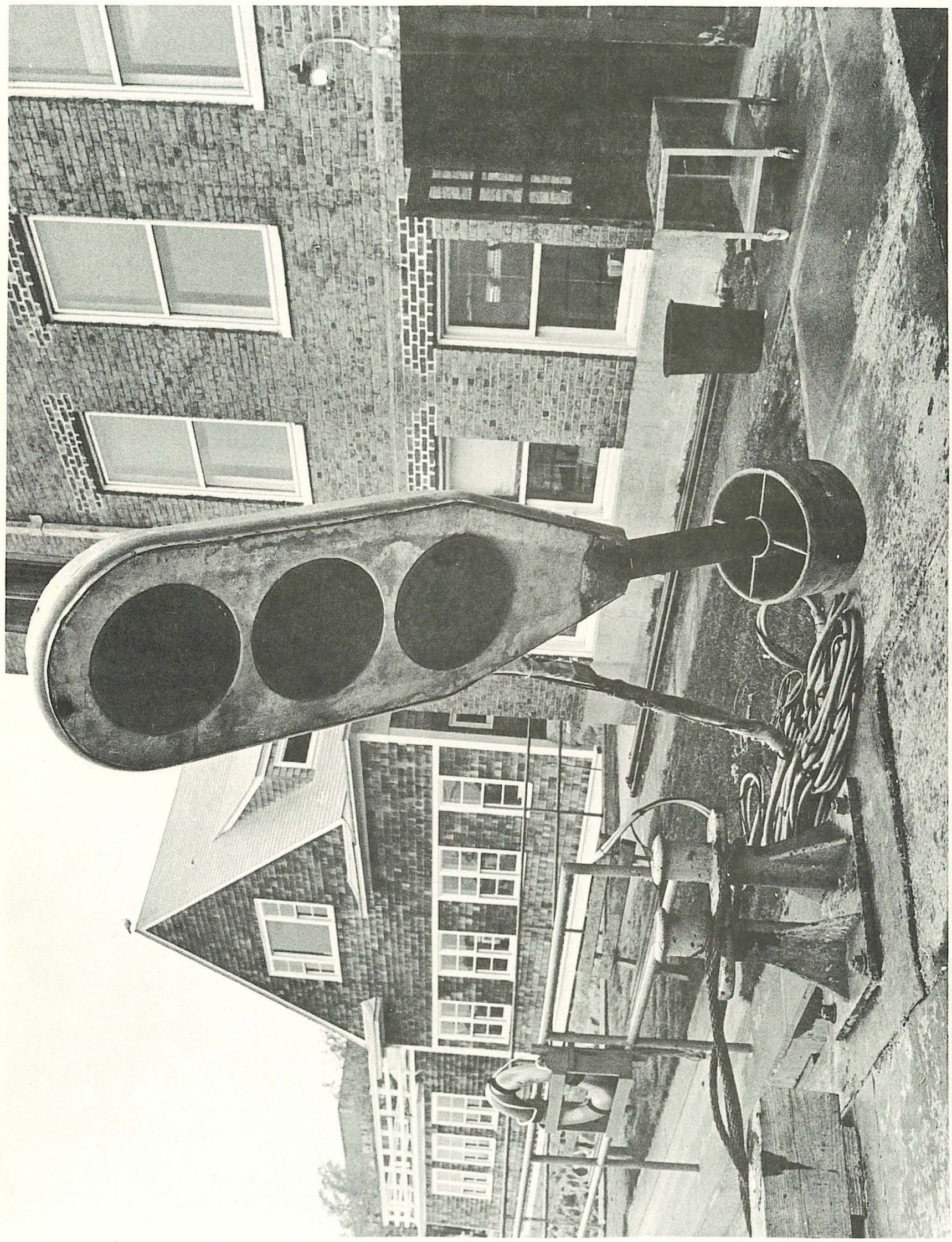

$m$
0
$y$
5
0
0
$0-1$
$i=1$ 


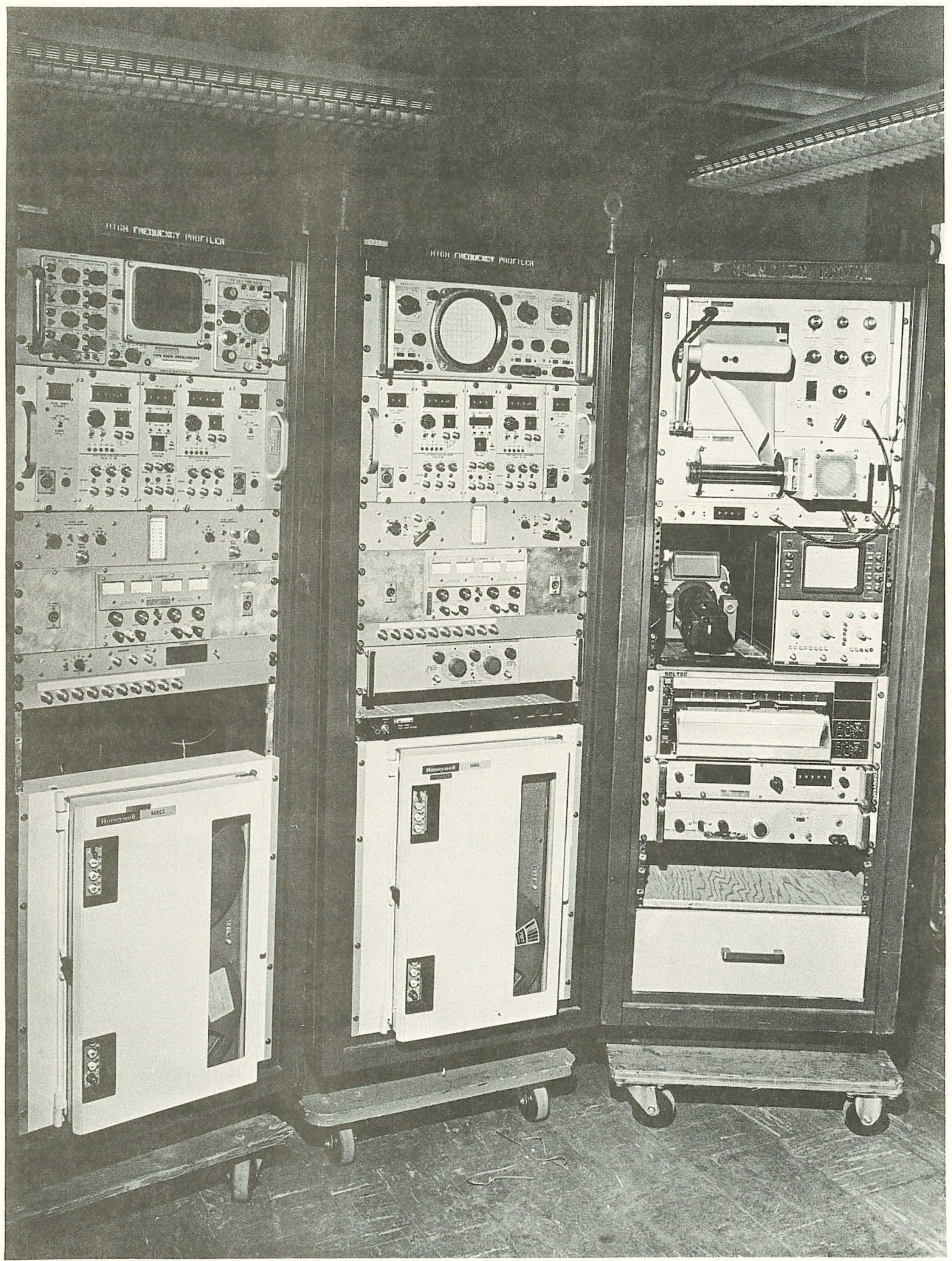




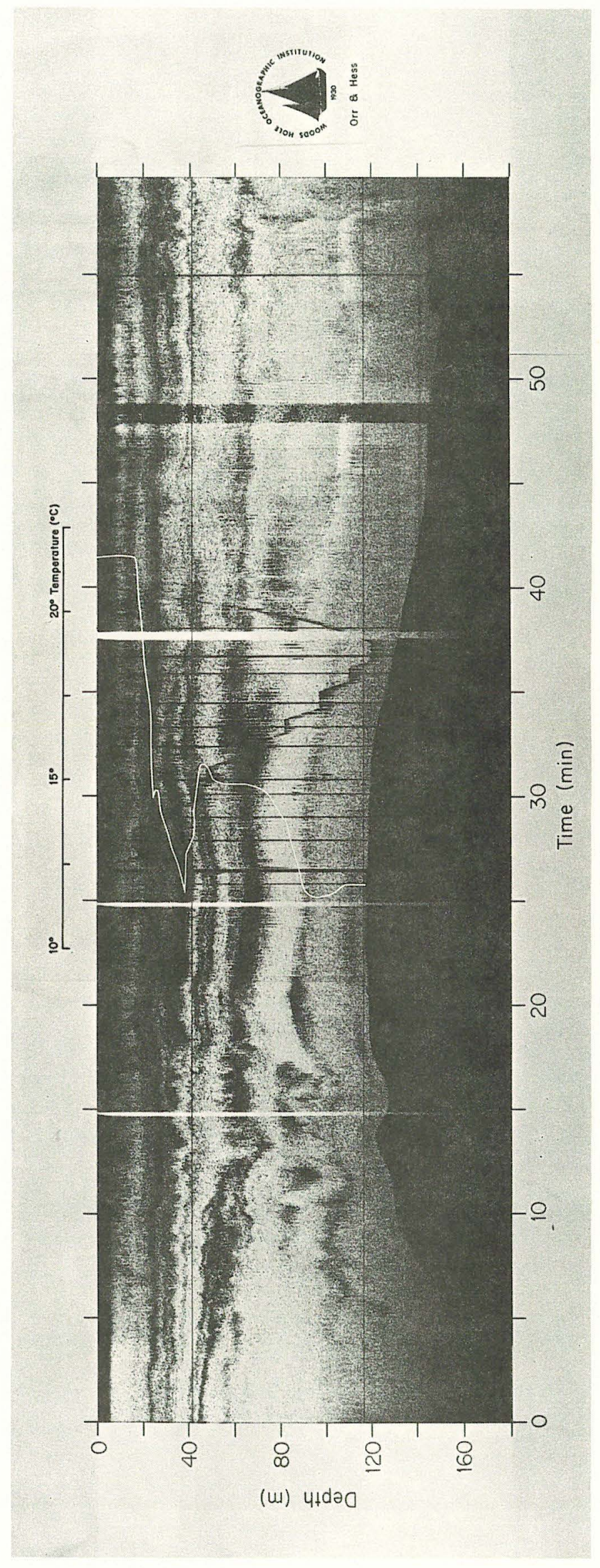

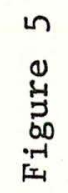


MANDATORY DISTRIBUTION LIST

FOR UNCLASSIFIED TECHNICAL REPORTS, REPRINTS, AND FINAL REPORTS PUBLISHED BY OCEANOGRAPHIC CONTRACTORS

OF THE OCEAN SCIENCE AND TECHNOLOGY DIVISION

OF THE OFFICE OF NAVAL RESEARCH

(REVISED NOVEMBER 1978)

1 Deputy Under Secretary of Defense (Research and Advanced Technology) Military Assistant for Environmental Science Room 3D129

Washington, D.C. 20301

Office of Naval Research 800 North Quincy Street

Arlington, VA 22217

3 ATTN: Code 483

1 ATTN: Code 460

2 ATTN: 102B

1 CDR J. C. Harlett, (USN)

ONR Representative

Woods Hole Oceanographic Inst.

Woods Hole, MA 02543

Commanding Officer

Naval Research Laboratory

Washington, D.C. 20375

6 ATTN: Library, Code 2627
12 Defense Documentation Center Cameron Station Alexandria, VA 22314

ATTN: DCA

Commander

Naval Oceanographic Office NSTL Station

Bay St. Louis, MS 39522

1 ATTN: Code 8100

1 ATTN: Code 6000

1 ATTN: Code 3300

1 NODC/NOAA

Code D781

Wisconsin Avenue, N.W. Washington, D.C. 20235 


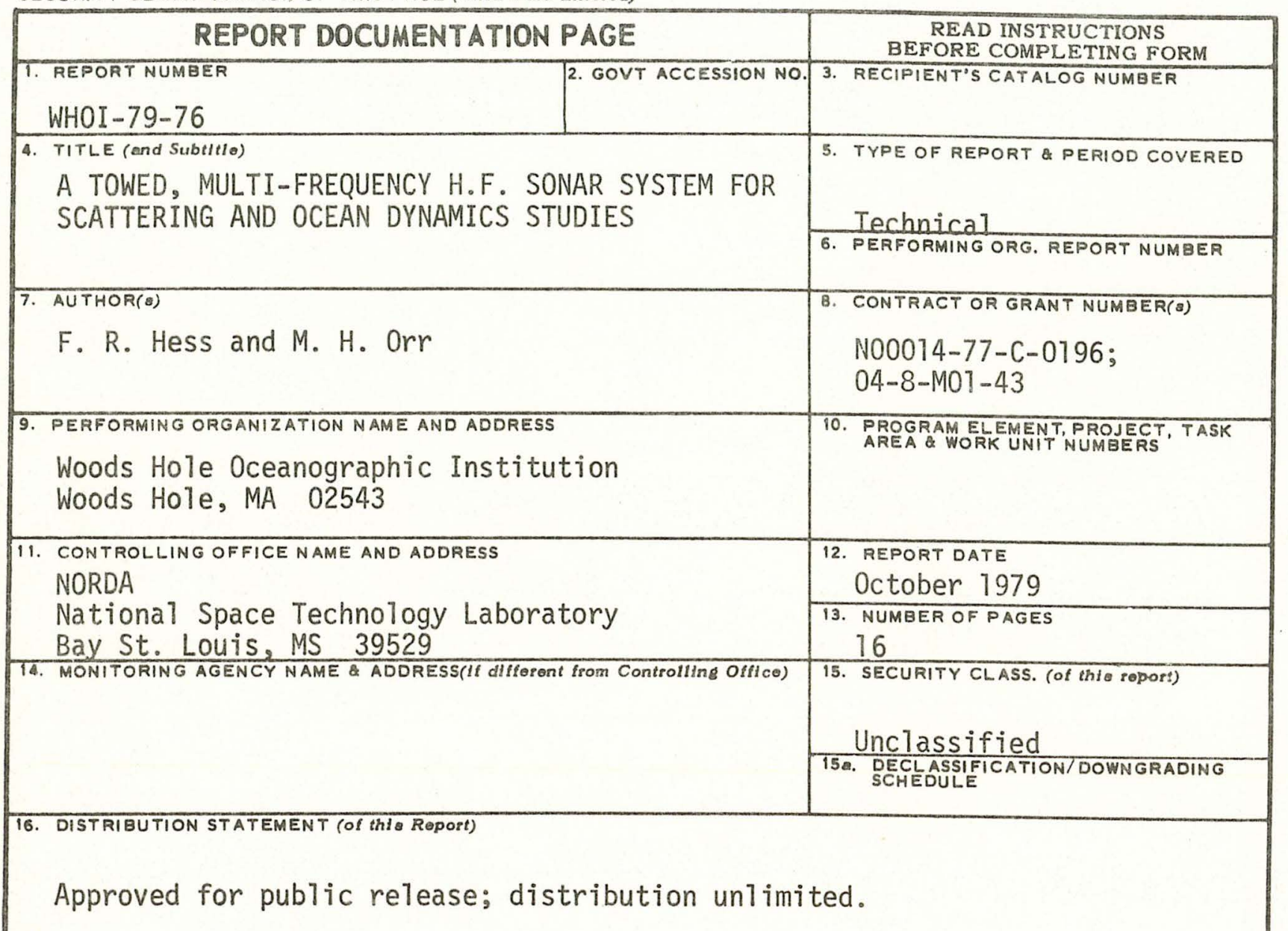

17. DISTRIBUTION STATEMENT (of the abatract entored in Block 20, il different from Roport)

18. SUPPLEMENTARY NOTES

19. KEY WORDS (Continue on soverse oldo if nocoseary and identlfy by block number)

1. Acoustics

2. Sonar

3. Scattering

4. Backscattering

20. ABSTRACT (Continue on reverse elde if neceecary end ldentlfy by block number)

The system described provides wide operational flexibility at any operating frequency from $5 \mathrm{kHz}$ to over $800 \mathrm{kHz}$ (except for a small band around $455 \mathrm{kHz}$ ) 7 imited mainly by the availability of transducers. Variable pulse width, variable receiver bandwidth, low receiver noise, various time variable gain functions and wide system dynamic range characterized the system. Built-in time-sharing controls maximize flexibility of graphics display on either drypaper or fibre-optic CRT recorders. 


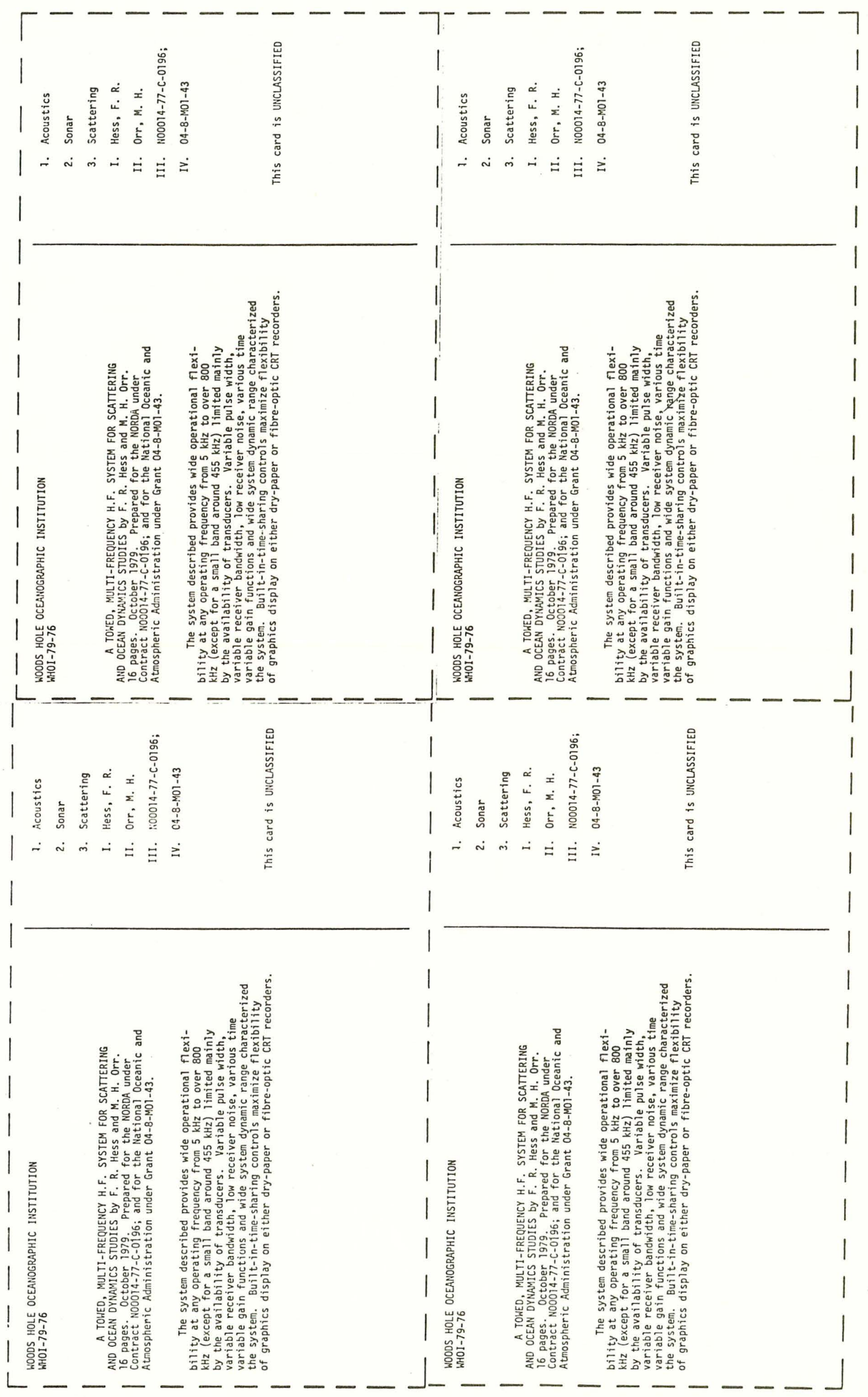

